\title{
Light-Driven $\mathrm{CO}_{2}$ Reduction by Co-Cytochrome $b_{562}$
}

\author{
Rafael Alcala-Torano, Nicholas Halloran, Noah Gwerder, Dayn J. Sommer and \\ Giovanna Ghirlanda*
}

School of Molecular Sciences, Arizona State University, Tempe, AZ, United States

The current trend in atmospheric carbon dioxide concentrations is causing increasing concerns for its environmental impacts, and spurring the developments of sustainable methods to reduce $\mathrm{CO}_{2}$ to usable molecules. We report the light-driven $\mathrm{CO}_{2}$ reduction in water in mild conditions by artificial protein catalysts based on cytochrome $b_{562}$ and incorporating cobalt protoporphyrin IX as cofactor. Incorporation into the protein scaffolds enhances the intrinsic reactivity of the cobalt porphyrin toward proton reduction and $\mathrm{CO}$ generation. Mutations around the binding site modulate the activity of the enzyme, pointing to the possibility of further improving catalytic activity through rational design or directed evolution.

\section{OPEN ACCESS}

Edited by:

Nikolaos E. Labrou,

Agricultural University of Athens,

Greece

Reviewed by:

Kamlendra Singh,

Karolinska Institute, Sweden

Christopher Berndsen,

James Madison University,

United States

*Correspondence:

Giovanna Ghirlanda

gghirlanda@asu.edu

Specialty section:

This article was submitted to Protein Chemistry and Enzymology,

a section of the journal

Frontiers in Molecular Biosciences

Received: 23 September 2020

Accepted: 11 January 2021

Published: 15 April 2021

Citation:

Alcala-Torano R, Halloran N,

Gwerder N, Sommer DJ and Ghirlanda $\mathrm{G}$ (2021) Light-Driven $\mathrm{CO}_{2}$

Reduction by Co-Cytochrome $b_{562}$.

Front. Mol. Biosci. 8:609654.

doi: 10.3389/fmolb.2021.609654
Keywords: cobalt porphyrin, Carbon fixation, $\mathrm{CO}_{2}$ reduction, catalysis, protein design, proton reduction

\section{INTRODUCTION}

The ongoing use of fossil fuels has led to an increase in atmospheric $\mathrm{CO}_{2}$ concentrations, causing severe consequences for the environment (Lacis et al., 2010). Current research efforts are focused on developing energetic alternatives that can help curb $\mathrm{CO}_{2}$ emissions. Although nature aids in the removal of this greenhouse gas through photosynthesis (Sun et al., 2014; Kondo et al., 2018), negative emissions technologies are necessary to reduce the excess gas from the atmosphere (Smith et al., 2015). One possible path is through artificial photosynthesis, where light is utilized as the energy source to drive production of carbon-free or carbon-neutral fuels, mirroring the role of the enzyme RuBisCO in fixing $\mathrm{CO}_{2}$. In that vein, promising approaches interfacing photosensitizers and/or materials with molecular catalysts, enzymes, and microorganisms have been developed (Woo, 2017; Luan and Lu, 2018; Edwards and Bren, 2020; Ma et al., 2020).

Artificial metalloenzymes obtained by incorporating organometallic catalysts within a protein bridge traditional molecular catalysts and enzymes, with the advantage of expanding the range of reactivity encountered in natural enzymes. Protein scaffolds may aide the efficiency of the organometallic center by offering tunable primary and secondary coordination spheres, by facilitating reactant binding and product release to and from the active site, and by protecting the organometallic center from degradation ( $\mathrm{Lu}$ et al., 2009; AlcalaTorano et al., 2016; Schwizer et al., 2018; Davis and Ward, 2019; Nastri et al., 2019; Oohora et al., 2019; Vornholt et al., 2020). This approach has been used to produce water-soluble catalysts that are capable of producing hydrogen from protons under mild conditions, repurposing a diverse group of organometallic catalysts (Sano et al., 2011; Roy et al., 2012; Kleingardner et al., 2014; Onoda et al., 2014; Sommer et al., 2014; Sommer et al., 2016; Firpo et al., 2018; Call et al., 2019a; Slater et al., 2019; Walsh et al., 2019; Alvarez-Hernandez et al., 2020; Laureanti et al., 2020; Le et al., 2020; Roy et al., 2020). Comparatively little work has been carried out on the reduction of $\mathrm{CO}_{2}$ by hybrid metalloenzymes: in one example nickel cyclam complexes anchored to azurin support catalytic $\mathrm{CO}_{2}$ reduction, with evidence of protein 
modulation of activity compared to the isolated cyclam (Schneider and Shafaat, 2016; Liu et al., 2018; Schneider et al., 2018).

Here, we investigate whether coordination of CoPPIX within a protein scaffold would support carbon dioxide reduction, motivated by recent reports of metalloporphyrins as molecular $\mathrm{CO}_{2}$ reduction electrocatalysts (Manbeck and Fujita, 2015; Mondal et al., 2015; Zhang et al., 2017; Birdja et al., 2018; Rao et al., 2018) and most recently photocatalysts (Call et al., 2019b; Fukuzumi et al., 2019). In these catalysts, tuning the reaction conditions or modifying the porphyrin framework in order to stabilize catalytic intermediates through hydrogen bonding resulted in increased activities of these catalysts toward $\mathrm{CO}_{2}$ reduction (Bhugun et al., 1996; Lee et al., 2011; Costentin et al., 2012; Azcarate et al., 2016a; b; Call et al., 2019b). Further, increased turnover numbers (TON) and product selectivity upon incorporation of cobalt porphyrins into supramolecular structures such as metal-organic frameworks (Kornienko et al., 2015; Lin et al., 2015; Zhang et al., 2016; Feng et al., 2020; Wu et al., 2020; Zhang et al., 2020) and polymers (Kramer and McCrory, 2016; Liu and McCrory, 2019) suggest that catalysis by cobalt porphyrins could be enhanced by incorporation into a protein environment. Our approach utilizes a natural protein scaffold, cytochrome $b_{562}$ (cyt $b_{562}$ ), in which the native heme has been swapped with its cobalt analog, cobalt protoporphyrin IX (CoPPIX). Our group and others have previously demonstrated that exchanging the metal ion to cobalt in heme-binding proteins or peptides results in metalloproteins that can catalyze proton reduction activity, and show an increase of $\mathrm{H}_{2}$ production compared to the cobalt porphyrin in solution. Moreover, altering the protein sequence results in fine modulation of the total activity, further supporting the crucial role of the protein environment throughout the catalytic cycle, beyond simple encapsulation (Kleingardner et al., 2014; Sommer et al., 2014; Sommer et al., 2016; Firpo et al., 2018; Le and Bren, 2019; Alvarez-Hernandez et al., 2020; Le et al., 2020). Compared with other supramolecular systems, proteins are easily modifiable by mutating the amino acid sequence, allowing the systematic exploration of the primary and secondary coordination sphere. Recent advances dramatically expand the range of chemical moieties available on the side chains through incorporation of noncanonical amino acids (Alcala-Torano et al., 2016; Burke et al., 2019; Drienovská et al., 2020; Drienovská and Roelfes, 2020; Zhou and Roelfes, 2020). Further, proteins can be optimized by directed evolution coupled with high-thrughput screening to identify favorable mutations (Liang et al., 2019; Chen and Arnold, 2020; Jeong et al., 2020; Markel et al., 2020).

\section{MATERIAL AND METHODS}

All chemicals were purchased from Sigma-Aldrich and used without further purification unless otherwise noted. Calibration gases were obtained from Matheson in $14 \mathrm{~L}$ lecture bottles. All aqueous solutions were prepared using deionized water with a resistivity greater or equal to $18 \mathrm{M} \Omega$. Cobalt (III) protoporphyrin IX chloride was purchased from Sigma-Aldrich and used without further purification.

\section{Protein Expression}

Mutants were generated in a pET30c (+) vector encoding WT cyt $b_{562}$ using mutagenic primers by Gibson assembly as described in Supplementary Information (Supplementary Table S1 and Supplementary Figure S8) (Sommer et al., 2016). The verified mutants were transformed into Escherichia coli BL21 (DE3) and grown in $1 \mathrm{~L}$ of $2 \mathrm{xTY}$ media at $37^{\circ} \mathrm{C}$ with shaking at $300 \mathrm{rpm}$. Cells were induced with $1 \mathrm{mM}$ IPTG at an $\mathrm{OD}_{600}$ of 0.6 and harvested after $4 \mathrm{~h}$ of expression. The cell pellets were suspended in $20 \mathrm{mM}$ Tris- $\mathrm{HCl}, 1 \mathrm{mM}$ DTT, $0.5 \mathrm{mM}$ EDTA and lysed by multiple cycles of ultrasonication. The clarified lysate was brought to $75 \%$ saturation with solid ammonium sulfate, and precipitated proteins were removed by centrifugation. The supernatant, containing the cytochrome mutants, was dialyzed against two changes of $10 \mathrm{mM}$ Tris $\mathrm{pH} 7.5$ and one of water at $4{ }^{\circ} \mathrm{C}$. Following dialysis, the protein solution was lyophilized and redissolved in $10 \mathrm{mM} \mathrm{NaCl}$ water for further purification via RPHPLC, using a semi-preparatory scale $\mathrm{C} 18$ column with a linear $1 \% \mathrm{~min}^{-1}$ gradient from $100 \%$ solvent $\mathrm{A}(0.1 \% \mathrm{v} / \mathrm{v}$ TFA in water $)$ to $100 \%$ solvent $\mathrm{B}$ ( $4.9 \% \mathrm{v} / \mathrm{v}$ water, $0.1 \% \mathrm{v} / \mathrm{v}$ TFA in acetonitrile). The fractions containing the desired protein were then lyophilized to yield the pure apo-protein. The protein identities were confirmed via MALDI-TOF-MS and their purity determined by C18 analytical analysis (Supplementary Information, Supplementary Figure S9). The purified protein was lyophilized and stored at $-78{ }^{\circ} \mathrm{C}$. Protein stocks were prepared by dissolving the protein in the appropriate phosphate buffer. The protein stock concentration was determined by UV spectroscopy in $6 \mathrm{M}$ urea using an extinction coefficient of $2980 \mathrm{M}^{-1} \mathrm{~cm}^{-1}$ at $280 \mathrm{~nm}$.

\section{Binding Assays}

The dissociation constant $\left(K_{\mathrm{d}}\right)$ of each mutant was assessed by titrating a solution of CoPPIX in $200 \mathrm{mM}$ potassium phosphate buffer at $\mathrm{pH} 7.5$ with a solution of the apo protein, and monitoring the absorbance of the Soret peak corresponding to the holo protein $(\sim 425 \mathrm{~nm}$ depending on the mutant) (Supplementary Figure S2). The initial CoPPIX concentration was determined using the observed absorbance value at the Soret peak of the free porphyrin $(417 \mathrm{~nm})$ and $\varepsilon=143,540 \mathrm{M}^{-1} \mathrm{~cm}^{-1}$ (as determined by ICP-OES experiments). All titrations were carried out in an anaerobic chamber (Coy Laboratory Products) equipped with UV-Vis (Ocean Optics USB4000). Data were fitted to Eq. 1 using OriginLab as described in the Supplementary Information by adapting established procedures (Hulme and Trevethick, 2010; Kovacs et al., 2010; Thordarson, 2011).

$$
\begin{aligned}
\Delta A=\frac{\Delta \varepsilon}{2} & \left([C y t]_{T}+[C o P P I X]_{T}+K_{d}\right. \\
& \left.-\sqrt{\left([C y t]_{T}+[C o P P I X]_{T}+K_{d}\right)^{2}-4[C o P P I X]_{T}[C y t]_{T}}\right),
\end{aligned}
$$

$\Delta A$ and $\Delta \varepsilon$ are the differences in absorbance and in extinction coefficients, respectively, between the free porphyrin and the holo protein at the latter's Soret peak $(\sim 425 \mathrm{~nm})$. [CoPPIX $]_{\mathrm{T}}$ is the 
total CoPPIX concentration, and $[\mathrm{Cyt}]_{\mathrm{T}}$ is the total protein concentration after each addition.

\section{Circular Dichroism Spectroscopy}

CD spectra were recorded on a JASCO J-815 spectropolarimeter in the range of $200-280 \mathrm{~nm}$ using a $1 \mathrm{~mm}$ cuvette. Data points were recorded every $1 \mathrm{~nm}$ and averaged over three scans. The protein concentration was kept at $5 \mu \mathrm{M}$ in $10 \mathrm{mM}$ phosphate buffer $\mathrm{pH} 7.5$ and the spectra was recorded at $20{ }^{\circ} \mathrm{C}$. Holo protein measurements were carried out in excess CoPPIX $(20 \mu \mathrm{M})$. Thermal denaturation was performed by heating samples from 4 to $90{ }^{\circ} \mathrm{C}$ at a rate of $1^{\circ} \mathrm{C} \min ^{-1}$, monitoring the loss of signal at $222 \mathrm{~nm}$.

\section{Photocatalytic Experiments}

Reactions were carried out in sealed cuvettes. Stock buffer containing $200 \mathrm{mM}$ potassium phosphate and $125 \mathrm{mM}$ ascorbic acid at pH 6.0 was bubbled with either $\mathrm{CO}_{2}$ or Ar, and adjusted back to $\mathrm{pH} 6.0$ with aqueous $\mathrm{KOH}$ if necessary. Finally, solid $\left[\mathrm{Ru}(\mathrm{bpy})_{3}\right] \mathrm{Cl}_{2} \cdot 6 \mathrm{H}_{2} \mathrm{O}$ was added to a $1.25 \mathrm{mM}$ final concentration, flash frozen in aliquots, and stored at $-80{ }^{\circ} \mathrm{C}$. Before each assay, CoPPIX was dissolved in $100 \mathrm{mM} \mathrm{KOH}$ to make a saturated solution, and the stock concentration was determined by UV-Vis using the Soret peak at $417 \mathrm{~nm}$ with an extinction coefficient of $\varepsilon=143,540 \mathrm{M}^{-1} \mathrm{~cm}^{-1}$ (as determined by ICP-OES measurements). The frozen buffer was thawed under an atmosphere of either $\mathrm{CO}_{2}$ or Ar, and CoPPIX and/or protein (in $200 \mathrm{mM}$ potassium phosphate) added to obtain working solutions containing $20 \mu \mathrm{M}$ CoPPIX, $30 \mu \mathrm{M}$ protein, $100 \mathrm{mM}$ ascorbic acid, and $1 \mathrm{mM}\left[\mathrm{Ru}(\mathrm{bpy})_{3}\right]^{2+}$ in $200 \mathrm{mM}$ potassium phosphate. The ratio of CoPPIX to apo protein was chosen from equilibrium calculations based on the highest observed $K_{\mathrm{d}}$ value to ensure $\geq 95 \%$ of porphyrin was bound to the protein.

For each experiment, $400 \mu \mathrm{L}$ of sample was added to a $10 \mathrm{~mm} \times 1 \mathrm{~mm}$ gas tight cuvette of known headspace volume, and the headspace sparged with gas $\left(\mathrm{Ar}\right.$ or $\left.\mathrm{CO}_{2}\right)$ for $20 \mathrm{~min}$. The cuvettes were then irradiated with a white light LED source for $8 \mathrm{~h}$. All experiments were done in triplicate and the variation is reported as the standard deviation of the sample. The gaseous products, $\mathrm{H}_{2}$ and $\mathrm{CO}$, were quantified by removing $100 \mu \mathrm{L}$ from the headspace at time intervals, and analyzed with an SRI Instruments gas chromatograph equipped with a $3 \mathrm{ft} \times 1 / 8$ " molecular sieve $5 \AA$ packed column. $\mathrm{H}_{2}$ and $\mathrm{CO}$ were detected and quantified simultaneously from the same injection using a Thermal Conductivity Detector (TCD) and a Flame ionization Detector (FID) with a methanizer connected in series. The analytes were eluted using $\mathrm{Ar}$ as a carrier gas with a temperature program starting at $60{ }^{\circ} \mathrm{C}$ for $1 \mathrm{~min}$, ramping at $20^{\circ} \mathrm{C} \mathrm{min}{ }^{-1}$ until $80^{\circ} \mathrm{C}$, holding for $2 \mathrm{~min}$, ramping at $50{ }^{\circ} \mathrm{C} \mathrm{min}{ }^{-1}$ to $250^{\circ} \mathrm{C}$, and holding until the $\mathrm{CO}_{2}$ exited the instrument, with a retention time $\left(t_{\mathrm{R}}\right)$ ca. $12 \mathrm{~min}$. A peak corresponding to $\mathrm{H}_{2}$ was seen on the TCD channel at $t_{\mathrm{R}}$ of $0.400 \mathrm{~min}$, while the peak corresponding to $\mathrm{CO}$ appeared at $t_{\mathrm{R}}=3.42 \mathrm{~min}$ on the FID channel. Peak areas were converted to moles using a calibration curve (Supplementary Figures S4 and S5). After irradiation was stopped, the solution was frozen at $-80{ }^{\circ} \mathrm{C}$ for future analysis. Formate was quantified by diluting the sample to $10 \% \mathrm{v} / \mathrm{v} \mathrm{D}_{2} \mathrm{O}$ in

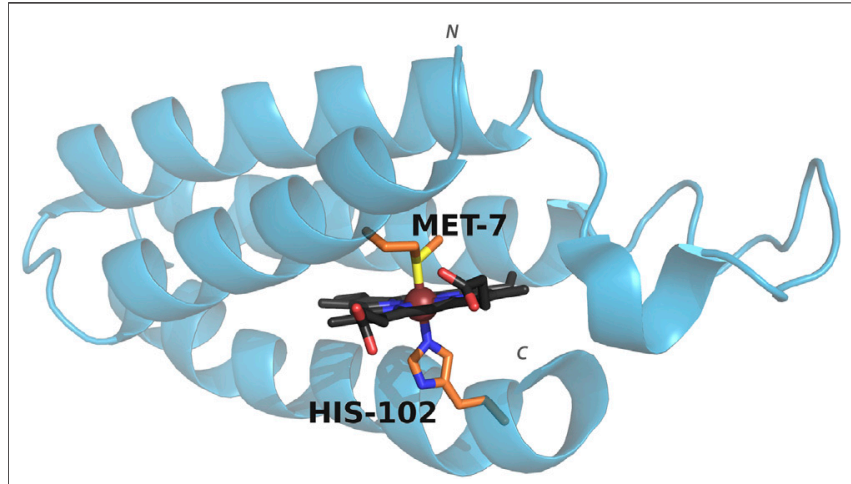

FIGURE 1 | Structure of cyt $b_{562}$ showing the coordinating axial ligands. PDB entry: 1QPU. Colors represent carbon (porphyrin: black, axial residues: orange), oxygen (red), nitrogen (blue), sulfur (yellow). The metal ion is shown as a sphere (brown). The $N$ and $C$ terminus are indicated.

water and $100 \mu \mathrm{M}$ sodium 4,4-dimethyl-1-silapentane-1- sulfonate (DSS) as an internal standard. The samples were then analyzed by ${ }^{1} \mathrm{H}$ NMR using a water suppression method with 64 scans and a $30 \mathrm{~s}$ relaxation delay. The formate concentration was determined by comparing the integration area of the singlet at $8.45 \mathrm{ppm}$ to the DSS peak at 0.0 ppm (Boston et al., 2013; Yehezkeli et al., 2016).

Turnover numbers (TON) are reported as the ratio of moles of product produced by moles of total CoPPIX present in solution. Comparisons between the means of each experiment were assessed using a two-tailed $t$-test analysis for samples with equal or unequal variances as determined by Levene's test. The null hypothesis $\left(\mathrm{H}_{0}: \bar{x}_{1}-\bar{x}_{2}=0\right)$ was rejected for $p$-values $<0.05$. The calculated $p$-values can be found in Supplementary Tables S2-S4 in the Supplementary Information.

\section{RESULTS AND DISCUSSION}

\section{Protein Design}

Cyt $b_{562}$ is a small, water-soluble, four-helix bundle that natively binds a heme cofactor via bis-axial ligation from the side chains of residues His102 and Met7 (Figure 1), and can coordinate a wide range of metalloporphyrins (Pia et al., 2012; Sommer et al., 2016; Bowen et al., 2020). Swapping in CoPPIX for heme and assessing activity under photocatalytic conditions results in a 10 fold increase in hydrogen production compared to CoPPIX in solution (Sommer et al., 2016). In order to facilitate binding of carbon dioxide and conversion to product, we utilized mutants that either remove axial ligation sites (M7A and H102A) or alter axial ligation (M7H) (Kamiya et al., 2001; Hay and Wydrzynski, 2005; Sommer et al., 2016). We assessed the effect of these mutations on the efficiency and specificity of $\mathrm{CO}_{2}$ reduction in water by cobalt porphyrins, which yields formate, carbon monoxide, and hydrogen in photocatalytic conditions.

We investigated the secondary structure and stability of the mutant proteins in the apo state and in response to binding to CoPPIX. The CD spectra of all apo mutants showed the typical 
TABLE 1 | CD and binding data for Co-cyt $b_{562}$ mutants. CD spectra was obtained at $20{ }^{\circ} \mathrm{C}$ in $10 \mathrm{mM}$ phosphate buffer $\mathrm{pH} 7.5$ with a protein concentration of $5 \mu \mathrm{M}$ and CoPPIX concentration of $20 \mu \mathrm{M}$. The $K_{\mathrm{d}}$ values were obtained using UV-Vis spectroscopy by titrating a stock solution of apo protein to a solution of CoPPIX of known concentration (see Methods and Supplementary Figures S1 and S2).

\begin{tabular}{lcccc} 
Mutant & \multicolumn{2}{c}{$\boldsymbol{T}_{\mathbf{m}}\left({ }^{\circ} \mathbf{C}\right)$} & $\Delta \boldsymbol{T}_{\mathbf{m}}\left({ }^{\circ} \mathbf{C}\right)$ & $\boldsymbol{K}_{\mathbf{d}}(\mathbf{n M})$ \\
\cline { 2 - 3 } & Apo & Holo & & \\
\hline WT & 56 & 72 & +16 & $45 \pm 19$ \\
M7A & 52 & 65 & +13 & $175 \pm 22$ \\
M7H & 50 & 75 & +25 & $559 \pm 89$ \\
H102A & 57 & 56 & -1 & $81 \pm 54$
\end{tabular}

signals of $\alpha$-helical proteins, with local minima at 208 and $222 \mathrm{~nm}$ (Supplementary Information, Supplementary Figure S1). Upon reconstitution with CoPPIX, WT and M7A show minimal changes in this region, indicating that incorporation of the cofactor has little effect on the structure of the protein at room temperature. The signal for $\mathrm{M} 7 \mathrm{H}$ increases upon addition of the porphyrin, showing that incorporation of the ligand stabilizes the secondary structure of the protein, possibly because coordination to the metal reduces the buried positive charges related to the two abutting histidines in the unoccupied active site. In contrast, H102A shows a decrease in signal upon addition of the porphyrin suggesting that this mutant adopts different apo and bound structures compared to the other mutants in the series (see discussion below).

More information on structural changes upon binding was gathered by comparing the stability of the mutants in the apo and holo state. We carried out unfolding experiments by monitoring the loss of intensity of the $222 \mathrm{~nm}$ peak in the CD spectrum at increasing temperature, obtaining thermal denaturation curves of the apo and holo mutants (SI, Supplementary Figure S1). The data presented in Table 1 shows that the apparent midpoint of the thermal denaturation, $T_{\mathrm{m}}$, increases significantly upon binding of the porphyrin, with the exception of $\mathrm{H} 102 \mathrm{~A}$, which showed a minimal change in its $T_{\mathrm{m}}$ value.

The stability of the apo state is strongly affected by mutations: compared to WT, the $T_{\mathrm{m}}$ of $\mathrm{M} 7 \mathrm{~A}$ is lowered $4{ }^{\circ} \mathrm{C}$, possibly due to a decrease in core hydrophobic volume, balanced by the high helical propensity of alanine compared to methionine (Chakrabartty et al., 1991). $\mathrm{M} 7 \mathrm{H}$ experiences a $6{ }^{\circ} \mathrm{C}$ destabilization. The solution structure of WT apo cyt $b_{562}$ (Feng et al., 1994) shows that His7 is largely solvent accessible, suggesting a $\mathrm{p} K_{\mathrm{a}}$ close to neutrality and indicating that the side chain can be partially charged under the experimental conditions (Edgcomb and Murphy, 2002). The observed destabilization correlates to lower helical propensity of histidine-particularly when ionized-compared to methionine (Pace and Scholtz, 1998). In contrast, H102A displays stability slightly higher than WT, because of the high helical propensity of alanine. Binding to CoPPIX stabilizes the proteins to an extent that reflects the changes in axial ligation: $\mathrm{M} 7 \mathrm{~A}$ is stabilized by $13^{\circ} \mathrm{C}$, a lesser extent than observed in WT $\left(16^{\circ} \mathrm{C}\right)$ because of the loss of axial ligand, while $\mathrm{M} 7 \mathrm{H}$ experiences much higher stabilization $\left(25^{\circ} \mathrm{C}\right)$ because of the strong double axial ligation afforded by histidine, and the loss of buried charges upon coordination. In $\mathrm{H} 102 \mathrm{~A}$, however, binding to CoPPIX does not increase stability. We speculate that comparable helical content and stabilities between the apo forms of H102A and WT arise from the small contribution of the C-terminal $\alpha$-helix to the folding of apo cyt $b_{562}$, because the C-terminus is unfolded in solution (PDB 1APC) (Feng et al., 1994). This observation suggests that folding of the C-terminal a-helix in the holo state of WT is predominantly driven by ligation of His102 to the porphyrin, and abolishing this interaction in $\mathrm{H} 102 \mathrm{~A}$ prevents folding of the bundle. In contrast, mutations to the axial position M7 have minimal effect on the stability of the holo protein: M7A is slightly destabilized compared to WT, while $\mathrm{M} 7 \mathrm{H}$ displays higher apparent $T_{\mathrm{m}}$, reflecting the relative strength of the axial coordination.

All mutants bind CoPPIX with $K_{\mathrm{d}}$ values in the low to midnanomolar range, as assessed through UV-Vis titration of apo protein to a solution of CoPPIX (SI, Supplementary Figure S2 and Table 1). However, displacement of either one of the native axial ligands weakens affinity, and all mutants bind CoPPIX with higher $K_{\mathrm{d}}$ values than WT. Among the mutants, H102A displays the highest affinity, similar to WT, followed by M7A; M7H registers the weakest affinity by far. This observation suggests that binding of the cofactor requires a pre-structured binding pocket in the apo state, as the affinity trend mirrors the trend observed for the stability of the apo forms.

\section{Photocatalytic Activity}

The Co-cyt $b_{562}$ mutants were assayed to investigate their ability to reduce $\mathrm{CO}_{2}$ under photoinduced conditions by using [Ru $\left.(\text { bpy })_{3}\right]^{2+}$ as photosensitizer and ascorbic acid as sacrificial electron donor. The excited state of $\left[\mathrm{Ru}(\mathrm{bpy})_{3}\right]^{2+}$ is reduced by ascorbic acid to $\left[\mathrm{Ru}(\mathrm{bpy})_{3}\right]^{+}$, which in turns transfers electrons to the catalyst resulting in substrate reduction (Morris et al., 2009). The Co-cyt $b_{562}$ mutants produced carbon monoxide and formate, in addition to $\mathrm{H}_{2}$ produced both in the presence and absence of $\mathrm{CO}_{2}$. Control experiments lacking CoPPIX showed little $\mathrm{H}_{2}$ was produced and no $\mathrm{CO}$ or $\mathrm{HCO}_{2}{ }^{-}$were detected, indicating that these species were produced by the cobalt catalyst. The reactivity observed is in line with previous mechanistic studies of cobalt porphyrins used as catalysts for these reactions (SI, Supplementary Figure S3) (Dhanasekaran et al., 1999; Morris et al., 2009; Leung et al., 2010; Nielsen and Leung, 2010; Shen et al., 2016; Call et al., 2019b).

The time-dependent results of the experiments are presented in Figure 2 and the final turnover numbers are shown on Table 2 and Figure 3. When assayed under a $\mathrm{CO}_{2}$ atmosphere at $\mathrm{pH} 6.0$, all mutants showed a two-fold increase in production of $\mathrm{CO}$ equivalent compared to the porphyrin alone, indicating that activity is increased by the interaction of the protein with the porphyrin (Table 2; Figures 2, 3). In contrast, activity toward formate production was similar to free porphyrin in all cases, with a slight decrease for M7A at $\mathrm{pH}$ 6.0. Observed $\mathrm{H}_{2}$ production activity at pH 6.0 was in all cases higher than CoPPIX, however with significant variation between mutants: M7A showed a $(20 \pm$ $5) \%$ increase in $\mathrm{H}_{2}$ compared to the porphyrin alone, followed by $\mathrm{M} 7 \mathrm{H}((45 \pm 7) \%)$ and WT $((72 \pm 7) \%, p=0.64$ for the M7H and 

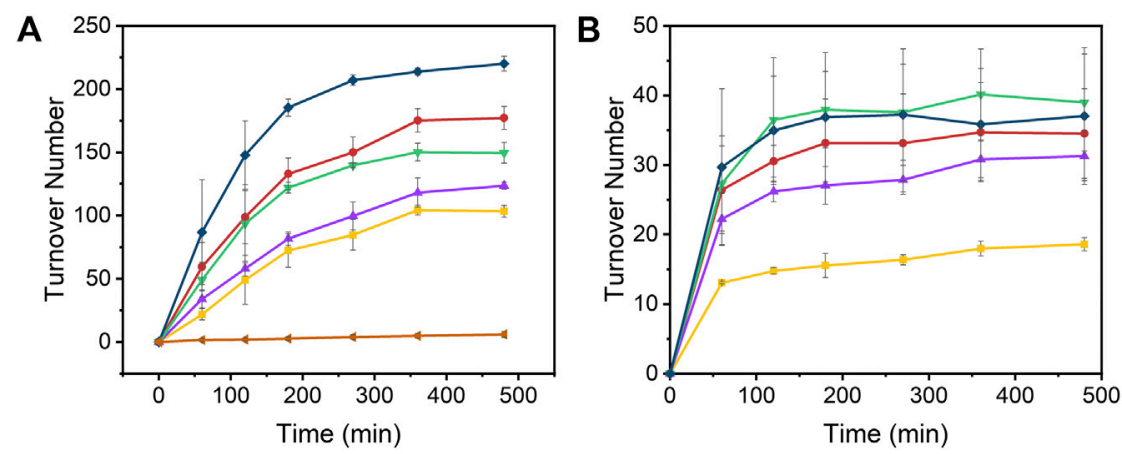

FIGURE 2 | Turnover number values of (A) $\mathrm{H}_{2}$ and (B) $\mathrm{CO}$ over time from the photoinduced reduction of protons by $\left[\mathrm{Ru}(\mathrm{bpy})_{3}\right]^{2+}$, CoPPIX, and Co-cyt $b_{562}$ mutants at $\mathrm{pH} 6.0$ under $1 \mathrm{~atm} \mathrm{CO}_{2}$. The experiments were carried out in $100 \mathrm{mM}$ ascorbic acid, $1 \mathrm{mM}\left[\mathrm{Ru}(\mathrm{bpy})_{3}\right]^{2+}, 200 \mathrm{mM}$ potassium phosphate, $20 \mu \mathrm{MM}$ CoPPIX (except in the negative control), and $30 \mu \mathrm{M}$ of corresponding apo cyt $b_{562}$ (except for free CoPPIX; apo WT cyt $b_{562}$ was used for the negative control) under white LED light irradiation. Colors represent $\left[\mathrm{Ru}(\mathrm{bpy})_{3}\right]^{2+}$ (negative control, orange side triangles), free CoPPIX (yellow squares), WT (red circles), M7A (purple up triangles), M7H (green down triangles), and H102A (dark blue diamonds). The TON for the negative control was calculated assuming a hypothetical catalyst content identical to the other samples $(8 \mathrm{nmol})$ for direct comparison. The experiments were run on triplicate and error bars represent the standard deviation of the sample.

TABLE 2 | Turnover numbers for the observed products under light irradiation in $200 \mathrm{mM}$ potassium phosphate, $100 \mathrm{mM}$ ascorbic acid, $1 \mathrm{mM}\left[\mathrm{Ru}(\mathrm{bpy})_{3}\right]^{2+}$, and 1 atm of gas.

\begin{tabular}{|c|c|c|c|c|c|c|c|}
\hline \multirow[t]{2}{*}{ Mutant } & \multicolumn{3}{|c|}{ TON H 2} & \multicolumn{2}{|c|}{ TON CO } & \multicolumn{2}{|c|}{ TON $\mathrm{HCO}_{2}^{-}$} \\
\hline & $\mathrm{pH} 6^{\mathrm{a}}$ & pH 6 & $\mathrm{pH} 7$ & pH 6 & pH 7 & pH 6 & pH 7 \\
\hline CoPPIX & $89 \pm 6$ & $103 \pm 5$ & $97 \pm 3$ & $19 \pm 1$ & $23 \pm 1$ & $33 \pm 4$ & $22 \pm 1$ \\
\hline M7A & $126 \pm 5$ & $124 \pm 3$ & $93 \pm 6$ & $31 \pm 4$ & $36 \pm 6$ & $20 \pm 3$ & $24 \pm 8$ \\
\hline $\mathrm{M} 7 \mathrm{H}$ & $167 \pm 10$ & $150 \pm 8$ & $143 \pm 6$ & $39 \pm 7$ & $42 \pm 11$ & $38 \pm 6$ & $35 \pm 14$ \\
\hline $\mathrm{H} 102 \mathrm{~A}$ & $205 \pm 16$ & $220 \pm 6$ & $163 \pm 7$ & $37 \pm 10$ & $33 \pm 10$ & $37 \pm 8$ & $25 \pm 8$ \\
\hline
\end{tabular}

${ }^{a}$ Control experiment under Ar instead of $\mathrm{CO}_{2}$.

WT comparison), and finally $\mathrm{H} 102 \mathrm{~A}$ with the highest increase in activity $[(113 \pm 5) \%]$. The assay was repeated in the absence of $\mathrm{CO}_{2}$ (Figure 3 and SI, Supplementary Figure S6), and yielded similar TON values for $\mathrm{H}_{2}$, indicating that overall $\mathrm{H}_{2}$ production is not affected by the presence of $\mathrm{CO}_{2}$. Methionine coordination at position seven results in a higher overall activity, as mutants bearing this residue (WT, $\mathrm{H} 102 \mathrm{~A}$ ) resulted in the highest TON values. A possible explanation of these observations is that as the metal center becomes more electron rich, a softer ligand-such as methionine's thioether side chain-is capable of better stabilizing the reduced intermediates that are formed throughout the catalytic cycle. Finally, the difference between the activities of H102A and WT could be due to the opening of a coordination site on one side of the porphyrin, thus increasing the chance of substrate binding to the active site. The near identical TONs observed for $\mathrm{CO}$ production as opposed to the variability observed for proton reduction suggests that the protein scaffold may provide proton relay pathways toward the active site. The rate limiting step of $\mathrm{CO}_{2}$ reduction to $\mathrm{CO}$ does not involve protonation steps, thus not benefiting in the same manner from the different proton environments as the $\mathrm{H}_{2}$-production cycle (Supplementary Figure S3).

The turnover numbers relative to $\mathrm{CO}$ production measured at pH 7.0 were generally unchanged for the holoprotein, while a

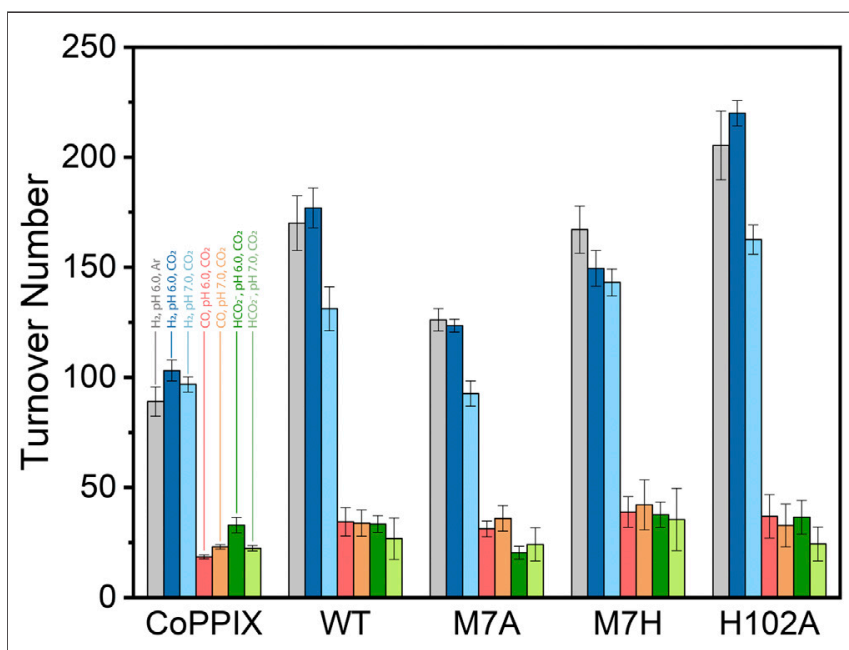

FIGURE 3 | Turnover number values obtained for CoPPIX and cobalt cyt $b_{562}$ mutants under irradiation with light for $8 \mathrm{~h}$ in $100 \mathrm{mM}$ ascorbic acid, $1 \mathrm{mM}\left[\mathrm{Ru}(\mathrm{bpy})_{3}\right]^{2+}$, and $200 \mathrm{mM}$ potassium phosphate. The bars represent the TON of each catalyst at $\mathrm{pH} 6.0$ in absence $\left(\mathrm{H}_{2}\right.$ : gray) and presence of $\mathrm{CO}_{2}\left(\mathrm{H}_{2}\right.$ : dark blue, $\mathrm{CO}$ : red, $\mathrm{HCO}_{2}^{-}$: dark green); and in the presence of $\mathrm{CO}_{2}$ at $\mathrm{pH} 7\left(\mathrm{H}_{2}\right.$ : light blue, $\mathrm{CO}$ : orange, $\mathrm{HCO}_{2}{ }^{-}$: light green). The experiments were run on triplicate and error bars represent the standard deviation of the sample. 
slight increase was recorded for CoPPIX. Unsurprisingly the $\mathrm{H}_{2}$ yield for WT, M7A, and H102A decreased by $20 \%$, as proton concentration is decreased 10 -fold. However, no statistically significant change was observed for the $\mathrm{H}_{2}$ TON of the free porphyrin or the $\mathrm{M} 7 \mathrm{H}$ mutant. Finally, a decrease in formate production was observed for the free porphyrin, consistent with the fact that its formation is dependent on proton concentration. The formate TON values for the holo proteins were not statistically different to those obtained at $\mathrm{pH} 6.0$, suggesting that the protein environment might serve as a proton source throughout this particular catalytic route, thus mitigating the effect of the lower proton concentration in solution.

\section{CONCLUSION}

We have investigated the effect of the primary coordination sphere provided by the protein environment of cobalt cytochrome $b_{562}$ in the light-promoted $\mathrm{CO}_{2}$ reduction pathway in mild aqueous conditions. Our results indicate that the native $\mathrm{CO}_{2}$ reduction activity of CoPPIX is increased when incorporated into the protein, whereas $\mathrm{HCO}_{2}{ }^{-}$production is not affected by the protein scaffold. Additionally, proton reduction showed a difference in activities between the mutants, suggesting that both electronic and steric effects play an important role throughout the catalytic cycle that leads to $\mathrm{H}_{2}$ production. Three of our protein scaffolds (WT, M7A, H102A) displayed $\mathrm{pH}$ dependance of proton reduction activity as expected, whereas $\mathrm{M} 7 \mathrm{H}$ and CoPPIX did not show any noticeable change in activity at the examined $\mathrm{pH}$ values. No $\mathrm{pH}$ dependence of $\mathrm{CO}_{2}$ reduction activity was observed between the catalysts, indicating that other factors may come into play in the mechanism of $\mathrm{CO}_{2}$ reduction by these catalysts.

This work illustrates the first example of light driven carbon dioxide reduction by a protein-cobalt porphyrin catalyst, and demonstrates that hybrid metalloenzymes can be generated by incorporating CoPPIX into cyt $b_{562}$; in water, the novel enzyme yields $\mathrm{CO}$, formate, and hydrogen. Hydrogen production activity is modulated by mutating residues involved in the first coordination sphere of the porphyrin; in contrast, the mutations investigated here do not affect significantly $\mathrm{CO}_{2}$

\section{REFERENCES}

Alcala-Torano, R. (2019). Rational metalloprotein design for energy conversion applications. Dissertation, Tempe (AZ): Arizona State University.

Alcala-Torano, R., Sommer, D. J., Bahrami Dizicheh, Z., and Ghirlanda, G. (2016). in Chapter seventeen-design strategies for redox active metalloenzymes: applications in hydrogen production. Methods in Enzymology. Editor V. L. Pecoraro (Academic Press), 389-416.

Alvarez-Hernandez, J. L., Sopchak, A. E., and Bren, K. L. (2020). Buffer $p K_{\mathrm{a}}$ impacts the mechanism of hydrogen evolution catalyzed by a cobalt porphyrin-peptide. Inorg. Chem. 59 (12), 8061-8069. doi:10.1021/acs. inorgchem.0c00362

Azcarate, I., Costentin, C., Robert, M., and Savéant, J.-M. (2016a). Dissection of electronic substituent effects in multielectron-multistep molecular catalysis. reduction. Further work explanding mutations in the first and second coordination sphere could provide insight into the mechanism(s) of photoinduced reduction of $\mathrm{H}^{+}$and $\mathrm{CO}_{2}$, which in turn could result in better catalysts for renewable energy and green chemistry.

\section{DATA AVAILABILITY STATEMENT}

The original contributions presented in the study are included in the article/Supplementary Material, further inquiries can be directed to the corresponding author.

\section{AUTHOR CONTRIBUTIONS}

RA-T, DS, and GG conceived the idea and designed the experiments. RA-T, DS, and NG performed the experiments. RA-T, NH, and GG analyzed the data. RA-T and GG wrote the article.

\section{FUNDING}

This work was supported by NSF SusChEM under Award 1508301 to GG.

\section{ACKNOWLEDGMENTS}

The authors would like to thank Brian Cherry (ASU) for help with setting up the NMR quantification of formate, and Dr. Kirtland J. Robinson for helpful discussions. The content of this manuscript has been published in part as part of the thesis of RAT (Alcala-Torano, 2019).

\section{SUPPLEMENTARY MATERIAL}

The Supplementary Material for this article can be found online at: https://www.frontiersin.org/articles/10.3389/fmolb.2021.609654/ full\#supplementary-material.

Electrochemical $\mathrm{CO}_{2}$-to-CO conversion catalyzed by iron porphyrins. J. Phys. Chem. C. 120 (51), 28951-28960. doi:10.1021/acs.jpcc.6b09947

Azcarate, I., Costentin, C., Robert, M., and Savéant, J.-M. (2016b). Through-space charge interaction substituent effects in molecular catalysis leading to the design of the most efficient catalyst of $\mathrm{CO}_{2}$-to-CO electrochemical conversion. J. Am. Chem. Soc. 138 (51), 16639-16644. doi:10.1021/jacs.6b07014

Bhugun, I., Lexa, D., and Savéant, J.-M. (1996). Catalysis of the electrochemical reduction of carbon dioxide by iron(0) porphyrins: synergystic effect of weak brönsted acids. J. Am. Chem. Soc. 118 (7), 1769-1776. doi:10.1021/ja9534462

Birdja, Y. Y., Vos, R. E., Wezendonk, T. A., Jiang, L., Kapteijn, F., and Koper, M. T. M. (2018). Effects of substrate and polymer encapsulation on $\mathrm{CO}_{2}$ electroreduction by immobilized indium(III) protoporphyrin. ACS Catal. 8 (5), 4420-4428. doi:10.1021/acscatal.7b03386

Boston, D. J., Xu, C., Armstrong, D. W., and MacDonnell, F. M. (2013). Photochemical reduction of carbon dioxide to methanol and formate in a 
homogeneous system with pyridinium catalysts. J. Am. Chem. Soc. 135 (44), 16252-16255. doi:10.1021/ja406074w

Bowen, B. J., McGarrity, A. R., Szeto, J.-Y. A., Pudney, C. R., and Jones, D. D. (2020). Switching protein metalloporphyrin binding specificity by design from iron to fluorogenic zinc. Chemical Commun. 56 (31), 4308-4311. doi:10.1039/ D0CC00596G

Burke, A. J., Lovelock, S. L., Frese, A., Crawshaw, R., Ortmayer, M., Dunstan, M., et al. (2019). Design and evolution of an enzyme with a non-canonical organocatalytic mechanism. Nature 570 (7760), 219-223. doi:10.1038/ s41586-019-1262-8

Call, A., Casadevall, C., Romero-Rivera, A., Martin-Diaconescu, V., Sommer, D. J., Osuna, S., et al. (2019a). Improved electro- and photocatalytic water reduction by confined cobalt catalysts in streptavidin. ACS Catal. 9 (7), 5837-5846. doi:10. 1021/acscatal.8b04981

Call, A., Cibian, M., Yamamoto, K., Nakazono, T., Yamauchi, K., and Sakai, K. (2019b). Highly efficient and selective photocatalytic $\mathrm{CO}_{2}$ reduction to $\mathrm{CO}$ in water by a cobalt porphyrin molecular catalyst. ACS Catal. 9 (6), 4867-4874. doi:10.1021/acscatal.8b04975

Chakrabartty, A., Schellman, J. A., and Baldwin, R. L. (1991). Large differences in the helix propensities of alanine and glycine. Nature 351 (6327), 586-588. doi:10.1038/351586a0

Chen, K., and Arnold, F. H. (2020). Engineering new catalytic activities in enzymes. Nature Catal. 3 (3), 203-213. doi:10.1038/s41929-019-0385-5

Costentin, C., Drouet, S., Robert, M., and Savéant, J.-M. (2012). A local proton source enhances $\mathrm{CO}_{2}$; electroreduction to $\mathrm{CO}$ by a molecular Fe catalyst. Science 338 (6103), 90. doi:10.1126/science.1224581

Davis, H. J., and Ward, T. R. (2019). Artificial metalloenzymes: challenges and opportunities. ACS Cent. Sci. 5 (7), 1120-1136. doi:10.1021/acscentsci.9b00397

Dhanasekaran, T., Grodkowski, J., Neta, P., Hambright, P., and Fujita, E. (1999). $p$-Terphenyl-Sensitized photoreduction of $\mathrm{CO}_{2}$ with cobalt and iron porphyrins. interaction between $\mathrm{CO}$ and reduced metalloporphyrins. J. Phys. Chem. 103 (38), 7742-7748. doi:10.1021/jp991423u

Drienovská, I., and Roelfes, G. (2020). Expanding the enzyme universe with genetically encoded unnatural amino acids. Nature Catalysis. 3 (3), 193-202. doi:10.1038/s41929-019-0410-8

Drienovská, I., Scheele, R. A., Gutiérrez de Souza, C., and Roelfes, G. (2020). A hydroxyquinoline-based unnatural amino acid for the design of novel artificial metalloenzymes. Chembiochem. 21, 3077-3081. doi:10.1002/cbic.202000306

Edgcomb, S. P., and Murphy, K. P. (2002). Variability in the $\mathrm{p} K_{\mathrm{a}}$ of histidine sidechains correlates with burial within proteins. Proteins: Structure, Function, and Bioinformatics. 49 (1), 1-6. 10.1002/prot.10177

Edwards, E. H., and Bren, K. L. (2020). Light-driven catalysis with engineered enzymes and biomimetic systems. Biotechnol. Appl. Biochem. 67, 463-483. doi:10.1002/bab1976

Feng, L., Wang, K.-Y., Joseph, E., and Zhou, H.-C. (2020). Catalytic porphyrin framework compounds. Trends Chem. 2 (6), 555-568. doi:10.1016/j.trechm. 2020.01 .003

Feng, Y., Sligar, S. G., and Wand, A. J. (1994). Solution structure of apocytochrome $b_{562}$. Nat. Struct. Biol. 1 (1), 30-35. doi:10.1038/nsb0194-30

Firpo, V., Le, J. M., Pavone, V., Lombardi, A., and Bren, K. L. (2018). Hydrogen evolution from water catalyzed by cobalt-monochrome $\mathrm{VI}^{*} \mathrm{a}$, a synthetic miniprotein. Chem. Sci. 9 (45), 8582-8589. doi:10.1039/C8SC01948G

Fukuzumi, S., Lee, Y.-M., and Nam, W. (2019). Photocatalytic redox reactions with metalloporphyrins. J. Porphyr. Phthalocyanines 24 (01n03), 21-32. doi:10.1142/ S1088424619300131

Hay, S., and Wydrzynski, T. (2005). Conversion of the Escherichia coli cytochrome $b_{562}$ to an archetype cytochrome $b$ : A mutant with bis-histidine ligation of heme iron. Biochemistry 44 (1), 431-439. doi:10.1021/bi0492298

Hulme, E. C., and Trevethick, M. A. (2010). Ligand binding assays at equilibrium: validation and interpretation. Br. J. Pharmacol. 161 (6), 1219-1237. doi:10. 1111/j.1476-5381.2009.00604.x

Jeong, W. J., Yu, J., and Song, W. J. (2020). Proteins as diverse, efficient, and evolvable scaffolds for artificial metalloenzymes. Chemical Commun. 56 (67), 9586-9599. doi:10.1039/D0CC03137B

Kamiya, N., Okimoto, Y., Ding, Z., Ohtomo, H., Shimizu, M., Kitayama, A., et al. (2001). How does heme axial ligand deletion affect the structure and the function of cytochrome $b_{562}$ ? Protein Eng. Des. Sel. 14 (6), 415-419. doi:10. 1093/protein/14.6.415
Kleingardner, J. G., Kandemir, B., and Bren, K. L. (2014). Hydrogen evolution from neutral water under aerobic conditions catalyzed by cobalt microperoxidase-11. J. Am. Chem. Soc. 136 (1), 4-7. doi:10.1021/ja406818h

Kondo, M., Ichii, K., Patra, P. K., Poulter, B., Calle, L., Koven, C., et al. (2018). Plant regrowth as a driver of recent enhancement of terrestrial $\mathrm{CO}_{2}$ uptake. Geophys. Res. Lett. 45 (10), 4820-4830. doi:10.1029/2018GL077633

Kornienko, N., Zhao, Y., Kley, C. S., Zhu, C., Kim, D., Lin, S., et al. (2015). Metalorganic frameworks for electrocatalytic reduction of carbon dioxide. J. Am. Chem. Soc. 137 (44), 14129-14135. doi:10.1021/jacs.5b08212

Kovacs, E., Tóth, J., Vértessy, B. G., and Liliom, K. (2010). Dissociation of calmodulin-target peptide complexes by the lipid mediator sphingosylphosphorylcholine: implications in calcium signaling. J. Biol. Chem. 285 (3), 1799-1808. doi:10.1074/jbc.M109.053116

Kramer, W. W., and McCrory, C. C. L. (2016). Polymer coordination promotes selective $\mathrm{CO}_{2}$ reduction by cobalt phthalocyanine. Chem. Sci. 7 (4), 2506-2515. doi:10.1039/C5SC04015A

Lacis, A. A., Schmidt, G. A., Rind, D., and Ruedy, R. A. (2010). Atmospheric $\mathrm{CO}_{2}$ : principal control knob governing earth's temperature. Science 330 (6002), 356. doi:10.1126/science.1190653

Laureanti, J. A., Ginovska, B., Buchko, G. W., Schenter, G. K., Hebert, M., Zadvornyy, O. A., et al. (2020). A positive charge in the outer coordination sphere of an artificial enzyme increases $\mathrm{CO}_{2}$ hydrogenation. Organometallics 39 (9), 1532-1544. doi:10.1021/acs.organomet.9b00843

Le, J. M., Alachouzos, G., Chino, M., Frontier, A. J., Lombardi, A., and Bren, K. L. (2020). Tuning mechanism through buffer dependence of hydrogen evolution catalyzed by a cobalt mini-enzyme. Biochemistry 59 (12), 1289-1297. doi:10. 1021/acs.biochem.0c00060

Le, J. M., and Bren, K. L. (2019). Engineered enzymes and bioinspired catalysts for energy conversion. ACS Energy Letters. 4 (9), 2168-2180. doi:10.1021/ acsenergylett.9b01308

Lee, C. H., Dogutan, D. K., and Nocera, D. G. (2011). Hydrogen generation by hangman metalloporphyrins. J. Am. Chem. Soc. 133 (23), 8775-8777. doi:10. 1021/ja202136y

Leung, K., Nielsen, I. M. B., Sai, N., Medforth, C., and Shelnutt, J. A. (2010). Cobaltporphyrin catalyzed electrochemical reduction of carbon dioxide in water. 2. mechanism from first principles. J. Phys. Chem. 114 (37), 10174-10184. doi:10. 1021/jp1012335

Liang, A. D., Serrano-Plana, J., Peterson, R. L., and Ward, T. R. (2019). Artificial metalloenzymes based on the biotin-streptavidin technology: enzymatic cascades and directed evolution. Acc. Chem. Res. 52 (3), 585-595. doi:10. 1021/acs.accounts.8b00618

Lin, S., Diercks, C. S., Zhang, Y.-B., Kornienko, N., Nichols, E. M., Zhao, Y., et al. (2015). Covalent organic frameworks comprising cobalt porphyrins for catalytic $\mathrm{CO}_{2}$ reduction in water. Science 349 (6253), 1208. doi:10.1126/ science.aac 8343

Liu, X., Kang, F., Hu, C., Wang, L., Xu, Z., Zheng, D., et al. (2018). A genetically encoded photosensitizer protein facilitates the rational design of a miniature photocatalytic $\mathrm{CO}_{2}$-reducing enzyme. Nat. Chem. 10 (12), 1201-1206. doi:10. 1038/s41557-018-0150-4

Liu, Y., and McCrory, C. C. L. (2019). Modulating the mechanism of electrocatalytic $\mathrm{CO}_{2}$ reduction by cobalt phthalocyanine through polymer coordination and encapsulation. Nat. Commun. 10 (1), 1683. doi:10.1038/ s41467-019-09626-8

Lu, Y., Yeung, N., Sieracki, N., and Marshall, N. M. (2009). Design of functional metalloproteins. Nature 460, 855. doi:10.1038/nature08304

Luan, G., and Lu, X. (2018). Tailoring cyanobacterial cell factory for improved industrial properties. Biotechnol. Adv. 36 (2), 430-442. doi:10.1016/j. biotechadv.2018.01.005

Ma, B., Chen, G., Fave, C., Chen, L., Kuriki, R., Maeda, K., et al. (2020). Efficient visible-light-driven $\mathrm{CO}_{2}$ reduction by a cobalt molecular catalyst covalently linked to mesoporous carbon nitride. J. Am. Chem. Soc. 142 (13), 6188-6195. doi:10.1021/jacs.9b13930

Manbeck, G. F., and Fujita, E. (2015). A review of iron and cobalt porphyrins, phthalocyanines and related complexes for electrochemical and photochemical reduction of carbon dioxide. J. Porphyr. Phthalocyanines 19 (01-03), 45-64. doi:10.1142/S1088424615300013

Markel, U., Essani, K. D., Besirlioglu, V., Schiffels, J., Streit, W. R., and Schwaneberg, U. (2020). Advances in ultrahigh-throughput screening for 
directed enzyme evolution. Chem. Soc. Rev. 49 (1), 233-262. doi:10.1039/ C8CS00981C

Mondal, B., Rana, A., Sen, P., and Dey, A. (2015). Intermediates involved in the $2 \mathrm{e}^{-} / 2 \mathrm{H}^{+}$reduction of $\mathrm{CO}_{2}$ to $\mathrm{CO}$ by iron(0) porphyrin. J. Am. Chem. Soc. 137 (35), 11214-11217. doi:10.1021/jacs.5b05992

Morris, A. J., Meyer, G. J., and Fujita, E. (2009). Molecular approaches to the photocatalytic reduction of carbon dioxide for solar fuels. Acc. Chem. Res. 42 (12), 1983-1994. doi:10.1021/ar9001679

Nastri, F., D’Alonzo, D., Leone, L., Zambrano, G., Pavone, V., and Lombardi, A. (2019). Engineering metalloprotein functions in designed and native scaffolds. Trends Biochem. Sci. 44 (12), 1022-1040. doi:10.1016/j.tibs.2019.06.006

Nielsen, I. M. B., and Leung, K. (2010). Cobalt-porphyrin catalyzed electrochemical reduction of carbon dioxide in water. 1. A density functional study of intermediates. J. Phys. Chem. 114 (37), 10166-10173. doi:10.1021/jp101180m

Onoda, A., Kihara, Y., Fukumoto, K., Sano, Y., and Hayashi, T. (2014). Photoinduced hydrogen evolution catalyzed by a synthetic diiron dithiolate complex embedded within a protein matrix. ACS Catal. 4 (8), 2645-2648. doi:10.1021/cs500392e

Oohora, K., Onoda, A., and Hayashi, T. (2019). Hemoproteins reconstituted with artificial metal complexes as biohybrid catalysts. Acc. Chem. Res. 52 (4), 945-954. doi:10.1021/acs.accounts.8b00676

Pace, C. N., and Scholtz, J. M. (1998). A helix propensity scale based on experimental studies of peptides and proteins. Biophys. J. 75 (1), 422-427. 10.1016/S0006-3495(98)77529-0

Pia, E. A. D., Chi, Q., Elliott, M., Emyr Macdonald, J., Ulstrup, J., and Dafydd Jones, D. (2012). Redox tuning of cytochrome $b_{562}$ through facile metal porphyrin substitution. Chemical Communications 48 (86), 10624-10626. doi:10.1039/ C2CC34302A

Rao, H., Lim, C.-H., Bonin, J., Miyake, G. M., and Robert, M. (2018). Visible-lightdriven conversion of $\mathrm{CO}_{2}$ to $\mathrm{CH}_{4}$ with an organic sensitizer and an iron porphyrin catalyst. J. Am. Chem. Soc. 140 (51), 17830-17834. doi:10.1021/jacs. $8 \mathrm{~b} 09740$

Roy, A., Madden, C., and Ghirlanda, G. (2012). Photo-induced hydrogen production in a helical peptide incorporating a $[\mathrm{FeFe}]$ hydrogenase active site mimic. Chemical Commun. 48 (79), 9816-9818. doi:10.1039/C2CC34470J

Roy, A., Vaughn, M. D., Tomlin, J., Booher, G. J., Kodis, G., Simmons, C. R., et al. (2020). Enhanced photocatalytic hydrogen production by hybrid streptavidindiiron catalysts. Chemistry 26 (28), 6240-6246. doi:10.1002/chem.202000204

Sano, Y., Onoda, A., and Hayashi, T. (2011). A hydrogenase model system based on the sequence of cytochrome c: photochemical hydrogen evolution in aqueous media. Chemical Commun. 47 (29), 8229-8231. doi:10.1039/C1CC11157D

Schneider, C. R., Manesis, A. C., Stevenson, M. J., and Shafaat, H. S. (2018). A photoactive semisynthetic metalloenzyme exhibits complete selectivity for $\mathrm{CO}_{2}$ reduction in water. Chemical Commun. 54 (37), 4681-4684. doi:10.1039/ C8CC01297K

Schneider, C. R., and Shafaat, H. S. (2016). An internal electron reservoir enhances catalytic $\mathrm{CO}_{2}$ reduction by a semisynthetic enzyme. Chemical Commun. 52 (64), 9889-9892. doi:10.1039/C6CC03901D

Schwizer, F., Okamoto, Y., Heinisch, T., Gu, Y., Pellizzoni, M. M., Lebrun, V., et al. (2018). Artificial metalloenzymes: reaction scope and optimization strategies. Chem. Rev. 118 (1), 142-231. doi:10.1021/acs.chemrev.7b00014

Shen, J., Kolb, M. J., Göttle, A. J., and Koper, M. T. M. (2016). DFT study on the mechanism of the electrochemical reduction of $\mathrm{CO}_{2}$ catalyzed by cobalt porphyrins. J. Phys. Chem. C 120 (29), 15714-15721. doi:10.1021/acs.jpcc. $5 \mathrm{~b} 10763$

Slater, J. W., Marguet, S. C., Gray, M. E., Monaco, H. A., Sotomayor, M., and Shafaat, H. S. (2019). Power of the secondary sphere: modulating hydrogenase activity in nickel-substituted rubredoxin. ACS Catal. 8928-8942. doi:10.1021/ acscatal.9b01720

Smith, P., Davis, S. J., Creutzig, F., Fuss, S., Minx, J., Gabrielle, B., et al. (2015). Biophysical and economic limits to negative $\mathrm{CO}_{2}$ emissions. Nat. Clim. Change 6, 42. doi:10.1038/nclimate2870
Sommer, D. J., Vaughn, M. D., Clark, B. C., Tomlin, J., Roy, A., and Ghirlanda, G. (2016). Reengineering cyt $b_{562}$ for hydrogen production: a facile route to artificial hydrogenases. Biochim. Biophys. Acta Bioenerg. 1857 (5), 598-603. doi:10.1016/j.bbabio.2015.09.001

Sommer, D. J., Vaughn, M. D., and Ghirlanda, G. (2014). Protein secondary-shell interactions enhance the photoinduced hydrogen production of cobalt protoporphyrin IX. Chemical Commun. 50 (100), 15852-15855. doi:10.1039/ C4CC06700B

Sun, Y., Gu, L., Dickinson, R. E., Norby, R. J., Pallardy, S. G., and Hoffman, F. M. (2014). Impact of mesophyll diffusion on estimated global land $\mathrm{CO}_{2}$ fertilization. Proc. Natl. Acad. Sci. Unit. States Am. 111, 15774-15779. doi:10.1073/pnas.1418075111

Thordarson, P. (2011). Determining association constants from titration experiments in supramolecular chemistry. Chem. Soc. Rev. 40 (3), 1305-1323. doi:10.1039/C0CS00062K

Vornholt, T., Christoffel, F., Pellizzoni, M. M., Panke, S., Ward, T. R., and Jeschek, M. (2020). Systematic engineering of artificial metalloenzymes for new-to-nature reactions, bioRxiv. 2007, 204206. doi:10.1101/2020.07.15. 204206

Walsh, A. P., Laureanti, J. A., Katipamula, S., Chambers, Geoffrey. M., Priyadarshani, N., Lense, S., et al. (2019). Evaluating the impacts of amino acids in the second and outer coordination spheres of Rh-bis(diphosphine) complexes for $\mathrm{CO}_{2}$ hydrogenation. Faraday Discuss 215 (0), 123-140. doi:10. 1039/C8FD00164B

Woo, H. M. (2017). Solar-to-chemical and solar-to-fuel production from $\mathrm{CO}_{2}$ by metabolically engineered microorganisms. Curr. Opin. Biotechnol. 45, 1-7. doi:10.1016/j.copbio.2016.11.017

Wu, Q., Xie, R.-K., Mao, M.-J., Chai, G.-L., Yi, J.-D., Zhao, S.-S., et al. (2020). Integration of strong electron transporter tetrathiafulvalene into metalloporphyrin-based covalent organic framework for highly efficient electroreduction of $\mathrm{CO}_{2}$. ACS Energy Letters 5 (3), 1005-1012. doi:10.1021/ acsenergylett.9b02756

Yehezkeli, O., Bedford, N. M., Park, E., Ma, K., and Cha, J. N. (2016). Semiconductor-based, solar-driven photochemical cells for fuel generation from carbon dioxide in aqueous solutions. ChemSusChem. 9 (22), 3188-3195. doi:10.1002/cssc.201601105

Zhang, H., Wei, J., Dong, J., Liu, G., Shi, L., An, P., et al. (2016). Efficient visiblelight-driven carbon dioxide reduction by a single-atom implanted metalorganic framework. Angew. Chem. Int. Ed. 55 (46), 14310-14314. doi:10. 1002/anie.201608597

Zhang, X.-D., Hou, S.-Z., Wu, J.-X., and Gu, Z.-Y. (2020). Two-dimensional metal-organic framework nanosheets with cobalt-porphyrins for highperformance $\mathrm{CO}_{2}$ electroreduction. Chem. Eur J. 26 (7), 1604-1611. doi:10. 1002/chem.201904072

Zhang, X., Wu, Z., Zhang, X., Li, L., Li, Y., Xu, H., et al. (2017). Highly selective and active $\mathrm{CO}_{2}$ reduction electrocatalysts based on cobalt phthalocyanine/carbon nanotube hybrid structures. Nat. Commun. 8, 14675. doi:10.1038/ ncomms 14675

Zhou, Z., and Roelfes, G. (2020). Synergistic catalysis in an artificial enzyme by simultaneous action of two abiological catalytic sites. Nature Catalysis. 3 (3), 289-294. doi:10.1038/s41929-019-0420-6

Conflict of Interest: The authors declare that the research was conducted in the absence of any commercial or financial relationships that could be construed as a potential conflict of interest.

Copyright (๑) 2021 Alcala-Torano, Halloran, Gwerder, Sommer and Ghirlanda. This is an open-access article distributed under the terms of the Creative Commons Attribution License (CC BY). The use, distribution or reproduction in other forums is permitted, provided the original author(s) and the copyright owner(s) are credited and that the original publication in this journal is cited, in accordance with accepted academic practice. No use, distribution or reproduction is permitted which does not comply with these terms. 